$$
\begin{aligned}
& 11.54 \\
& 030609
\end{aligned}
$$

NASA Technical Paper 3660

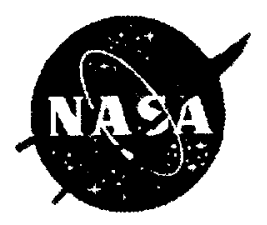

\title{
Development of the Space Operations Incident Reporting Tool (SOIRT)
}

Jacquie Minton

June 1997 


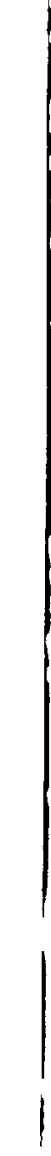

1 
NASA Technical Paper 3660

\section{Development of the Space Operations Incident Reporting Tool (SOIRT)}

Jacquie Minton

Lockheed Martin Engineering \& Science Services

Houston, Texas

June 1997 


\section{Acknowledgments}

This research was supported by Contract No. NAS9-18800 and Contract No. JE9019LN-3001 from the National Aeronautics and Space Administration (NASA), and conducted in the Human Factors and Ergonomics Laboratory, Johnson Space Center, Houston, Texas. We would like to thank Steve Chrisman and Dr. George Chandlee for proposing and initiating the space operations incident reporting tool, Dr. Kritina Holden for her extensive review and assistance and Dr. Frances Mount, the NASA technical monitor, for her review of the document. We would also like to thank the crews of STS-70 and STS-73 for their participation and support.

This publication is available from the Center for AeroSpace Information, 800 Elkridge Landing Road, Linthicum Heights, MD 21090-2934 (301) 621-0390 


\section{Contents}

\begin{tabular}{|c|c|}
\hline & 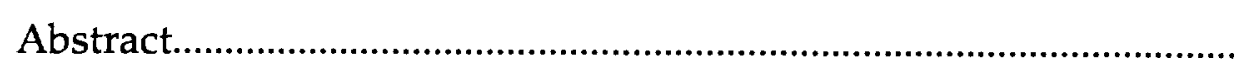 \\
\hline 1.0 & Introduction..... \\
\hline 2.0 & (1) \\
\hline 3.0 & 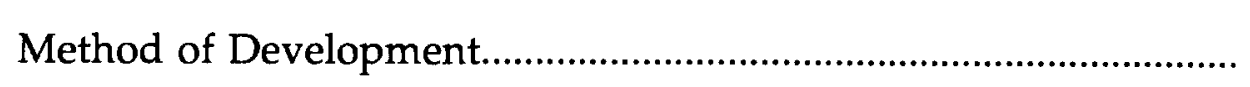 \\
\hline 4.0 & The SOIRT Form \\
\hline 5.0 & 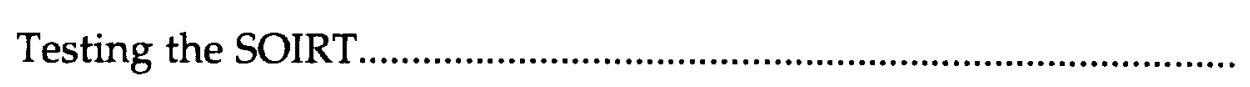 \\
\hline 5.1 & 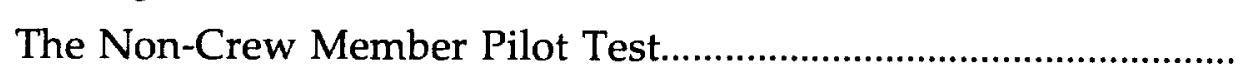 \\
\hline 5.1 .1 & Method \\
\hline 5.1.1.1 & Subjects................................................ \\
\hline 5.1.1.2 & 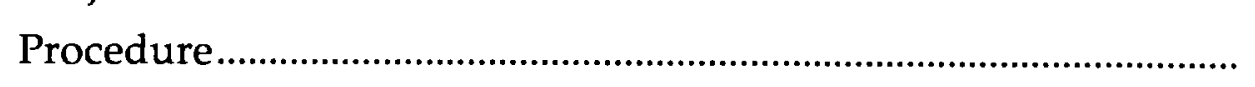 \\
\hline 5.1.1.3 & Results............................................... \\
\hline 5.1.1.4 & 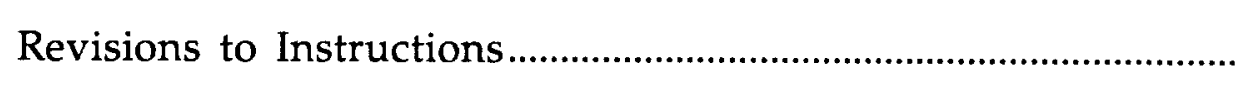 \\
\hline 5.2 & 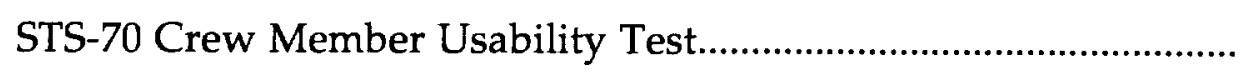 \\
\hline 5.2 .1 & 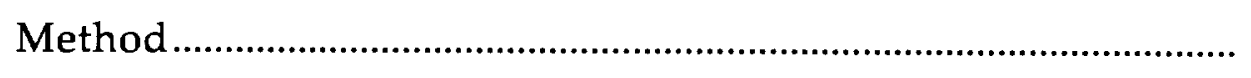 \\
\hline 5.2.1.1 & 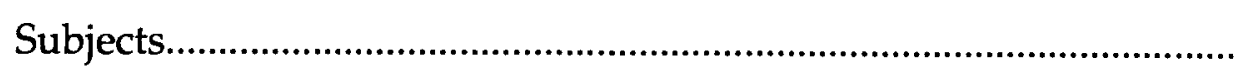 \\
\hline 5.2.1.2 & Procedure \\
\hline 5.2.1.3 & 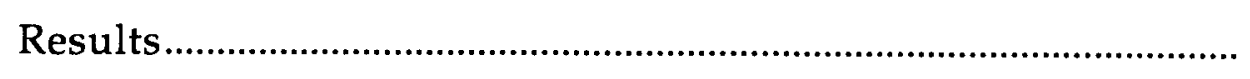 \\
\hline 5.3 & 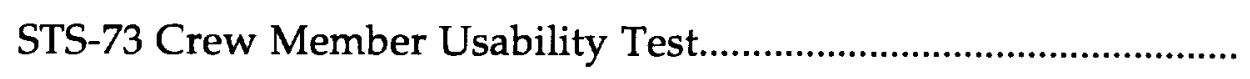 \\
\hline 5.3 .1 & Method \\
\hline 5.3.1.1 & Subjects...1. \\
\hline 5.3.1.2 & Procedure \\
\hline 5.3 .1 .3 & 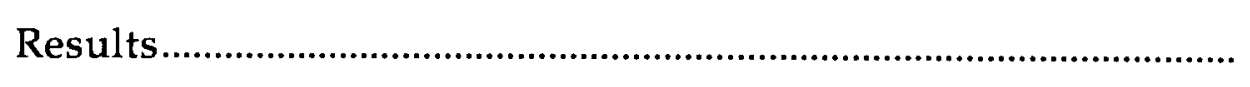 \\
\hline 6.0 & 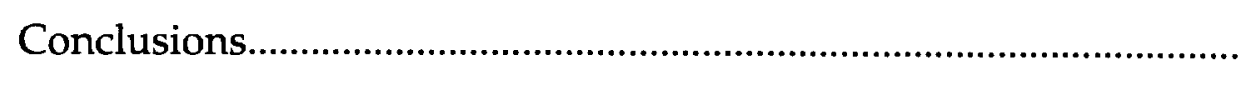 \\
\hline Appendix A & Space Operations Incident Reporting Tool Form ................................. \\
\hline Appendix B & 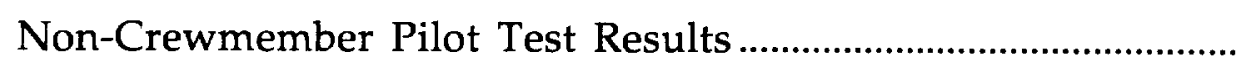 \\
\hline
\end{tabular}




\section{Acronyms}

ASRS aviation safety reporting system

SOIRT space operation incident reporting tool

STS space transportation system

NASA National Aeronautics and Space Administration 


\title{
Development of the Space Operations Incident Reporting Tool
}

\begin{abstract}
The space operations incident reporting tool (SOIRT) is an instrument used to record information about an anomaly occurring during flight which may have been due to insufficient and/or inappropriate application of human factors knowledge. The SOIRT form was originally developed after researching other incident reporting systems of this type. We modified the form after performing several in-house reviews and a pilot test to access usability. Finally, crew members from Space Shuttle flights STS (space transportation system)-70 and STS-73 participated in a usability test of the tool after their missions.

Since the National Aeronautics and Space Administration (NASA) currently has no system for continuous collection of this type of information, the SOIRT was developed to report issues such as reach envelope constraints, control operation difficulties, and vision impairments. However, if the SOIRT were to become a formal NASA process, information from crew members could be collected in a database and made available to individuals responsible for improving in-flight safety and productivity. Potential benefits include documentation to justify the redesign or development of new equipment/systems, provide the mission planners with a method for identifying past incidents, justify the development of timelines and mission scenarios, and require the creation of more appropriate work/rest cycles.
\end{abstract}

\subsection{Introduction}

With NASA's increased emphasis on safety and accident prevention, it is important to try to identify situations that could result in safety problems in the future.

Spacesuits that are difficult to don, controls that are difficult to operate, and displays that are non-intuitive, while not safety issues themselves, all have the potential of impacting mission safety and productivity.

NASA currently has no system for collecting reports of anomalies specifically related to human factors. Therefore, an incident reporting tool, the SOIRT, was developed. The SOIRT is a means for describing a human factors incident during space operations: what happened, where it happened, who was involved, why it happened, and any possible solutions. The SOIRT is intended to be used whenever human factors issues are suspect (e.g., reach envelope constrained by hardware, controls or switches that are difficult to operate, impaired vision due to glare). The SOIRT is also intended to be used to describe instances where human-machine interactions can be improved. It is not intended to be used to document incidents or 
events involving bodily harm or injury. This form should be used to compliment safety and/or accident reports when appropriate.

\subsection{Purpose}

The SOIRT's purpose is to provide a process for identifying human factors issues that impact space operations. Once documented, the incident reports could be integrated into a "lessons learned" database or similar-type database. The human factors issues identified could then be distributed to the appropriate organizations for resolution.

\subsection{Method of Development}

The SOIRT form was developed after researching other incident reporting systems in use. A model for the SOIRT exists in the form of the aviation safety reporting system (ASRS) program. The ASRS program was designed to gather data regarding aviation incidents, and to supplement information derived from aircraft accident investigations. During the SOIRT development process, we gathered a number of incidents from previous manned space flight missions to serve as test cases for the SOIRT. We then compiled the data from a variety of sources such as mission reports, flight crew debriefings, and crew questionnaires.

After several in-house reviews and a preliminary review by a crew representative, we performed a non-crew member pilot test to determine the SOIRT's usability. We then modified the form based on the non-crew member pilot test results. Finally, STS-70 and STS-73 crew members participated in a usability test of the tool after their missions. The crew member-suggested modifications to the SOIRT are now in progress.

\subsection{The SOIRT Form}

The SOIRT is a tool structured to allow operations personnel, flight controllers, and crew members a process for identifying human factors issues that impact space operations. (See Appendix A for a copy of the SOIRT used by STS-70 and STS-73 in their usability testing). It is divided into three sections after a brief introduction to the purpose of the SOIRT. The first section is titled "General Information" and contains information regarding personnel, location, time, date, and other information pertinent to the incident. The second section of the SOIRT is the "Description of Incident" and is a checklist regarding the incident. There are three category headings: "Environment," "Human," and "Equipment/Systems."

Personnel may check any items under each category that apply to the incident (many items will overlap in the different categories). An area is provided directly below this section to write a description of the incident. The third section of the SOIRT is 
"Causes \& Possible Solutions." There are three categories included in this section: minor modifications, significant modifications, and a complete hardware and/or software redesign. Personnel should check the appropriate category to define how severe the modifications are to preclude reccurrence of the incident. There is also a space provided for personnel to identify the cause of the incident, and provide suggestions for preventing recurrence of a similar incident in the future.

Two computerized versions of the SOIRT were developed after crew members requested an electronic format. The electronic formats of the SOIRT are in SuperCard® for the Macintosh and in Microsoft Visual Basic ${ }^{\circledR}$ for the IBMcompatible computer systems. Input fields were used for general information regarding personnel, the incident, and roles in the incident. Check boxes were used to check items in the description of the incident. On-line definitions were provided for the items found in the check boxes by depressing the shift key and clicking on the item to be defined. There was also an area provided to type in the description of the incident, the cause, and any possible solutions.

\subsection{Testing the SOIRT}

The SOIRT has been tested in three parts: the non-crew member pilot test, the STS-70 crew member usability test, and the STS-73 crew member usability test.

\subsection{The Non-Crew Member Pilot Test}

After several in-house reviews and a preliminary review by a crew representative, a non-crew member pilot test was performed to determine the SOIRT's usability. The objectives of the non-crew member pilot test group were 1) to determine whether the main category headings and the items found under each main category heading would be useful to a person unfamiliar with human factors in organizing their incident description, and 2) to determine and resolve any confusion that might result while using the SOIRT due to the directions or procedures of the form.

\subsubsection{Method}

5.1.1.1 Subjects. The non-crew member pilot test group consisted of 13 subjects: four co-operative students, two secretaries, two data entry technicians, two electrical engineers, one data processor, one human factors specialist, and one human factors associate.

5.1.1.2 Procedure. The subjects were briefed about the purpose of the experiment. They were then asked to read six examples of incidents that occurred on previous missions. After reading each example, the subjects were asked to identify human factors items under the main categories that contributed to the incident. 
The subjects were also asked to identify and categorize each incident using Categories I through III as to whether the incident needed minor modifications, significant modifications, or a complete hardware and/or software redesign.

The subjects answered a short questionnaire after categorizing the six incident examples. The questionnaire contained questions regarding the difficulty that each subject experienced while classifying the incidents.

5.1.1.3 Results. We graphed the data from the non-crew member pilot test, each example according to the frequency of responses for each category (Appendix B). Human factors professionals then evaluated the results independently to fine-tune categories, identify inconsistencies across the subject choices, and determine other problem areas. Comments from the subjects were also taken into consideration in evaluating the SOIRT form. The following table summarizes changes made to the form after the usability test.

Table 1. Revisions to the SOIRT Form After Usability Testing

\begin{tabular}{|c|c|c|}
\hline ORIGINAL & REVISED & REASON \\
\hline machine category & equipment/systems category & clarification \\
\hline operational category & -----deleted----- & concepts regrouped \\
\hline acoustics/noise & noise level & misunderstood \\
\hline confined space & available space & misunderstood \\
\hline atmosphere & air quality/pressure & misunderstood \\
\hline-- & comfort & subject suggestion \\
\hline cultural differences & cultural/language differences & clarification \\
\hline language & -----deleted----- & combined/clarity \\
\hline processing/calculation & mental processing & misunderstood \\
\hline 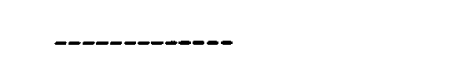 & procedures/training & concepts regrouped \\
\hline
\end{tabular}

5.1.1.4 Revisions to Instructions. We made two primary revisions to the SOIRT instructions: 1) the importance of the category headings was stressed, and 2) the proper use of the categories and items was clarified. In addition, we developed definitions and examples for each of the items (to be used as needed). 


\subsection{STS-70 Crew Member Usability Test}

The objectives of the STS-70 crew member test group were 1) to gain usability data on the SOIRT using a real environment/incident on the shuttle, 2) to acquire crew member input on the feasibility/merit of the SOIRT and 3) to acquire crew member ideas on developing the SOIRT into a formal NASA form/process.

\subsubsection{Method}

5.2.1.1 Subjects. The crew member usability test of the SOIRT consisted of the five crew members from the STS-70 mission.

5.2.1.2 Procedure. The SOIRT was given to the crew members of STS-70 after returning from their mission. Each crew member was given the choice of testing the SOIRT using the paper version or the computerized version. The crew members were also asked to answer a questionnaire regarding the SOIRT format and process.

5.2.1.3 Results. Data collected from the questionnaire included crew member responses to seven free-format questions (if they used the computerized version of the SOIRT, an additional set of six free-format questions was included). The crew members concluded that the SOIRT was a much-needed process at NASA. One crew member reported that the SOIRT would help to improve human factors in the future. When asked if they had any thoughts on how the SOIRT should be developed into a formal NASA form/process, one crew member responded that it should be integrated into standard debriefs. Another crew member suggested modelling the program after the safety form for aircraft incidents. Overall, the crew members' responses to the SOIRT were positive and helpful in reinforcing the importance of the SOIRT and its need in the space program.

\subsection{STS-73 Crew Member Usability Test}

\subsubsection{Method}

5.3.1.1 Subjects. Four out of the seven STS-73 crew members participated in the usability test of the SOIRT.

5.3.1.2 Procedure. The SOIRT was given to the crew members of STS-73 during the post-flight debrief. Each crew member was given the choice of testing the SOIRT using the paper version or the computerized version. The crew members were also asked to answer the same questionnaire given to STS-70 crew members regarding the SOIRT format and process.

5.3.1.3 Results. The crew members considered the SOIRT a very much needed project. They recommended changing the format of the SOIRT from an incident report to that of a suggestion form. The word "incident" implied that an actual 
event occurred which would need to be reported. Therefore, any confusion could be avoided by replacing the word "incident" with "suggestion." Crew members also commented that categorizing the incident in Part II, "Description of Incident," helped to structure their report. Other suggestions included broadening the categories and adding "reach" and "accessibility" classifications.

Crew members concluded that the SOIRT should be kept informal and could become a part of the crew equipment debrief after each mission. Overall, the crew members' responses were very positive, recognizing the need for the SOIRT in the space program.

\subsection{Conclusions}

Overall, crew members viewed the SOIRT as acceptable and ready for use. However, the crew members' comments and suggestions will be evaluated and incorporated before implementing the SOIRT.

Once implementation begins and information on the SOIRT form is collected from crew members, it could be entered into a database. The SOIRT database could contribute to more efficient and safe human exploration in microgravity environments. Benefits could include not only a process for justifying redesign or development of new equipment/systems, but also for providing mission planners with a method for identifying past incidents, developing timelines and mission scenarios, and developing schedules for more efficiency and safety.

The design of the SOIRT database could be applied directly to earth-based activities where complex operations and procedures are used. Earth operations that could benefit from the incident reporting tool include control rooms (power, chemical plant, and other), medical procedures, and submarine operations. 


\section{Appendix A}

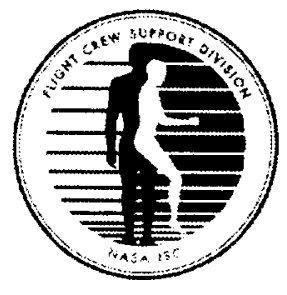

\section{Space Operations Incident Reporting Tool (SOIRT)}

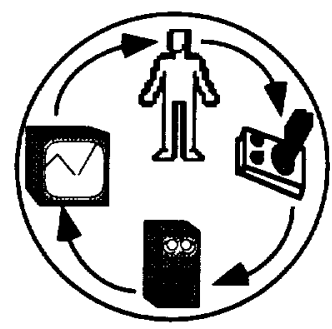

The purpose of the Space Operations Incident Reporting Tool (SOIRT) is to provide a process for identifying human factors issues that impact space operations.

Human factors is defined as discovering and applying information about human capabilities and limitations to help in the development of safe, comfortable and effective tools, machines, systems, tasks, jobs, and environments. The SOIRT should be used whenever human factors issues are suspect (e.g., reach envelope constrained by hardware, controls or switches that are difficult to operate, impaired vision due to glare).

The SOIRT is a means for describing a human factors incident: what happened, where it happened, who was involved, why it happened, and any possible solutions. An incident is defined as any event or anomaly that occurs during space related operations. Information gained from this form will be used to evaluate and improve processes and workplace designs.

THIS FORM SHOULD BE USED TO DESCRIBE INSTANCES WHERE HUMAN-MACHINE INTERACTIONS CAN BE IMPROVED. It should not be used to document incidents or events involving bodily harm or injury (use NASA Mishap Form 1627). This form should be used to compliment safety and/or accident reports when appropriate.

\section{General Information}

\begin{tabular}{|c|c|c|}
\hline \multirow{3}{*}{ = } & \multicolumn{2}{|l|}{ Name } \\
\hline & Job Title & Mail Code \\
\hline & Phone & Email Address \\
\hline $\overrightarrow{0}$ & Mission (if applicable) & Location \\
\hline$\vec{b}$ & Date & Time \\
\hline
\end{tabular}

Specify your role at time of incident (e.g. test conductor, subject, etc).

Specify the role of other persons involved in the incident.

For additional information contact Dr. Frances Mount at the following address: 


\section{Description of Incident}

Use the list below to help structure your description of the incident, paying particular attention to the category headings. Check any items und er each category that apply (many items will overlap in the different categories). When selecting items, determine whether each item, or the lack of the item contributed to the incident. The items under the Equipment /Systems category may be a computer, a switch, a display, crew personal equipment, a robotic arm, etc. After categorizing, write a description of the incident below. Include information that you feel is important for identification of the incident.

\begin{tabular}{|llll|}
\hline 1. Environment & 2. Human & & 3. Equipment/Systems \\
$\square$ lighting & $\square$ visual & $\square$ hygiene & $\square$ design \\
$\square$ noise level & $\square$ auditory & $\square$ memory & $\square$ labels \\
$\square$ vibration & $\square$ tactile & $\square$ mental processing & $\square$ controls/input devices \\
$\square$ temperature & $\square$ physical size & $\square$ sensory overload & $\square$ displays \\
$\square$ gravity & $\square$ mobility & $\square$ cultural/language & $\square$ warnings \\
$\square$ available space & $\square$ endurance & differences & $\square$ accuracy \\
$\square$ air quality $\backslash$ pressure & $\square$ strength & $\square$ procedures/training & $\square$ processing speed \\
$\square$ housekeeping & $\square$ comfort & $\square$ other & $\square$ reliability \\
$\square$ other & $\square$ physical stress/fatigue & $\square$ other \\
\hline
\end{tabular}

\section{Causes \& Possible Solutions}

Using the boxes below, please check the category of the incident. Also provide information that might help identify the cause of the incident, and suggestions for preventing recurrence of this incident in the future. Examples are:

1. "Information on the display changed too rapidly to make use of it. Solution: Provide history list of data ouptuts so that I can review them later."

2. "Radio frequency button is often pressed when trying to adjust volume. Solution: Separate controls or provide stiffer resistance for button to keep inadvertent presses from activating it.

$\square$ Category I Minor modifications to design or training procedure needed to rectify situation.

Category II Significant modifications to design or training are required.

$\square$ Category III Complete hardware and/or software redesign is required.

For additional information contact Dr. Frances Mount at the following address:

Space Operations Incident Reporting, Mail Code: SP34, NASA Johnson Space Center, Houston, Texas 77058 


\section{Appendix B \\ Non-Crewmember Pilot Test Results}
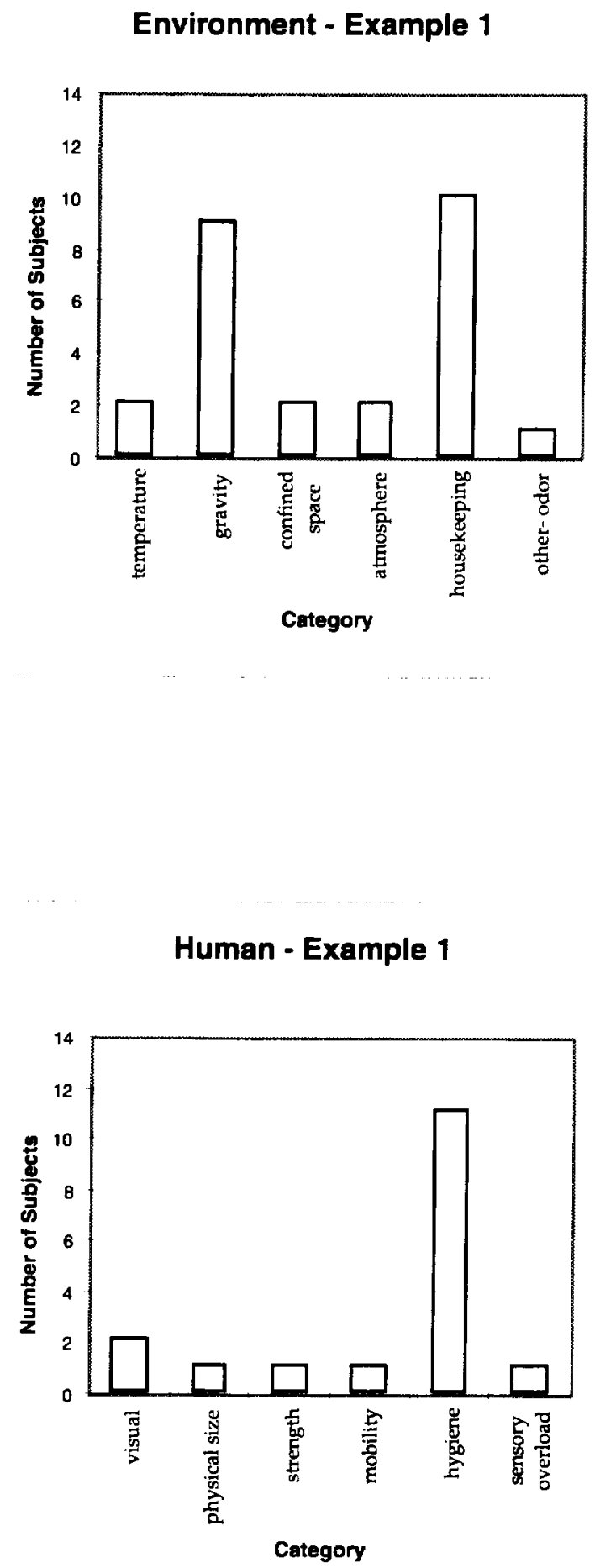

B-1 

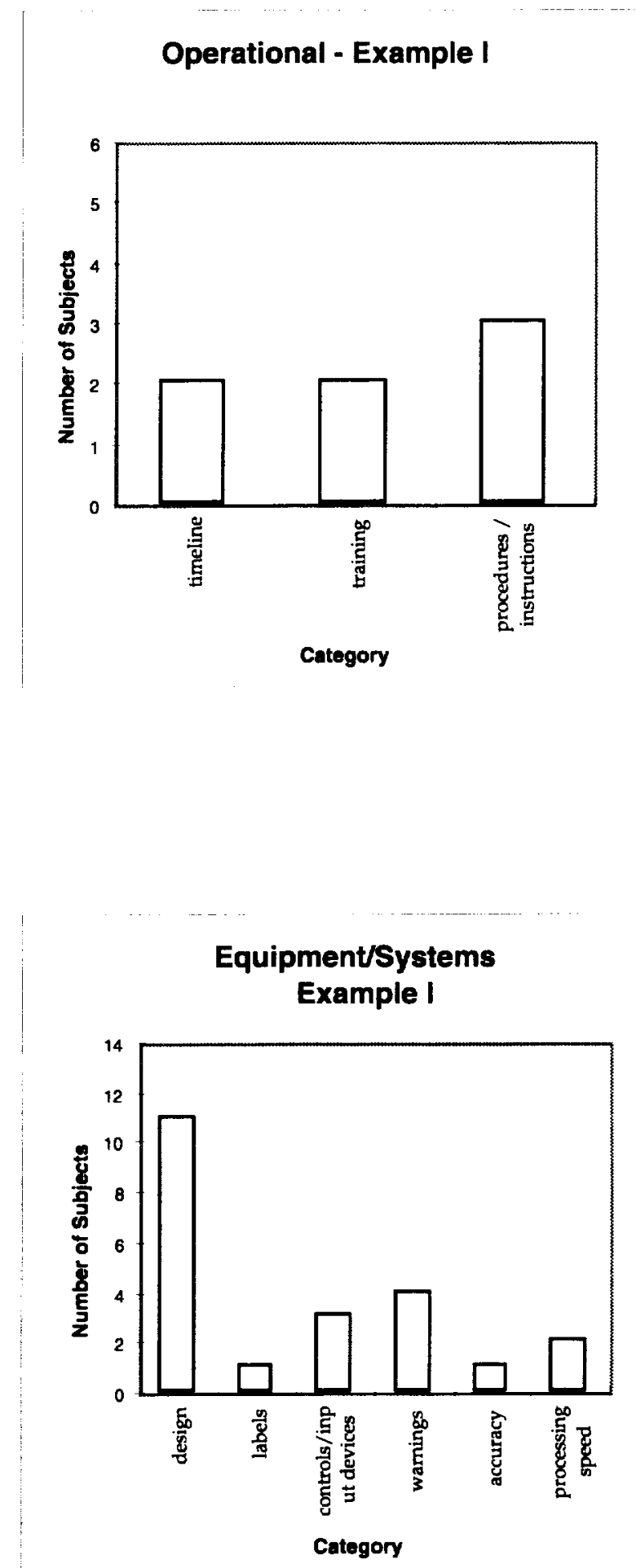

B-2 
Environment - Example II

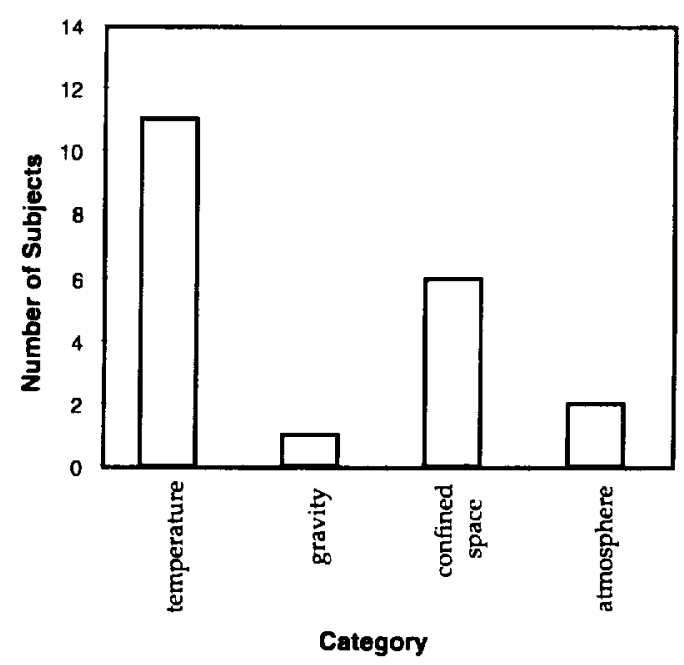

Human - Example II

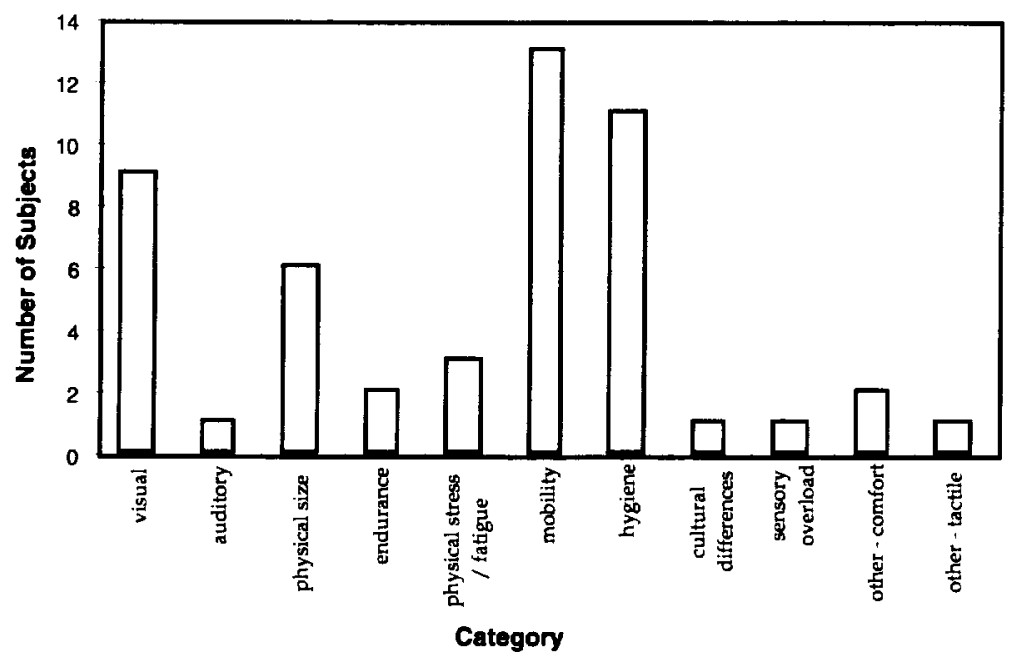

B-3 
Operational - Example II

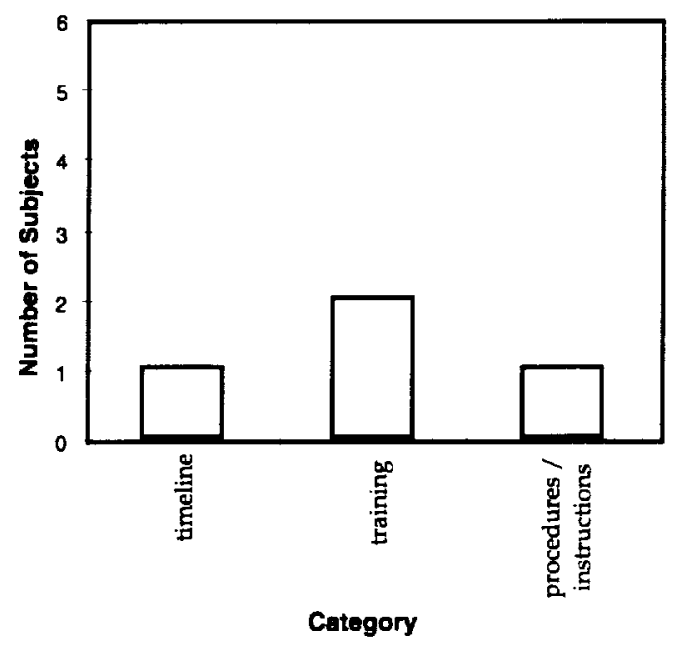

Equipment /System

Example II

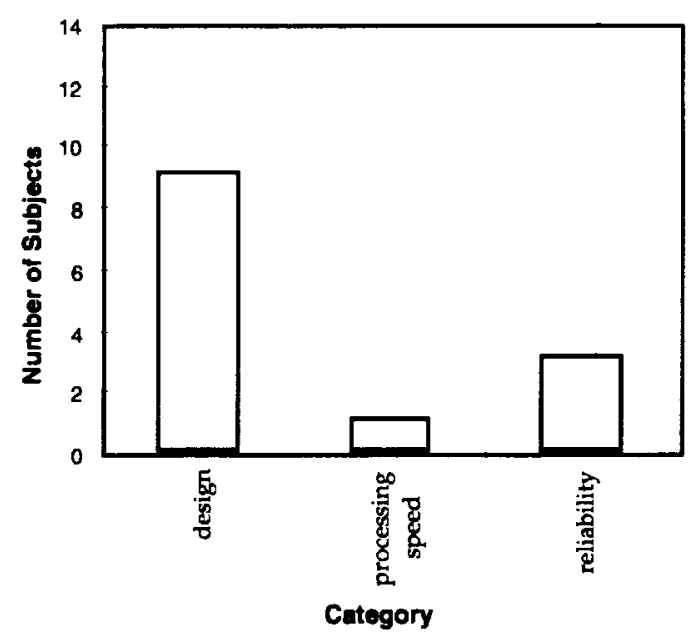

B-4 

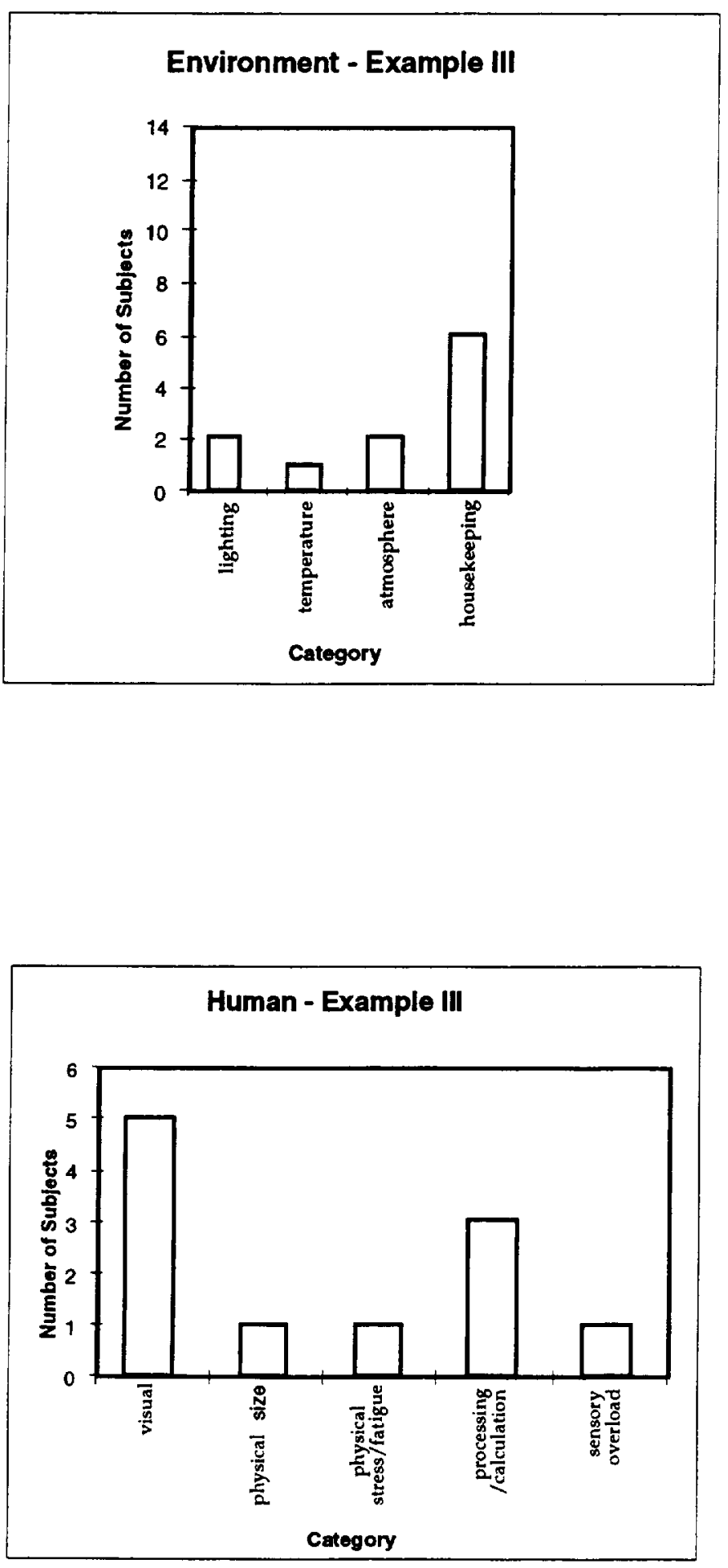

B-5 
Operational - Example III

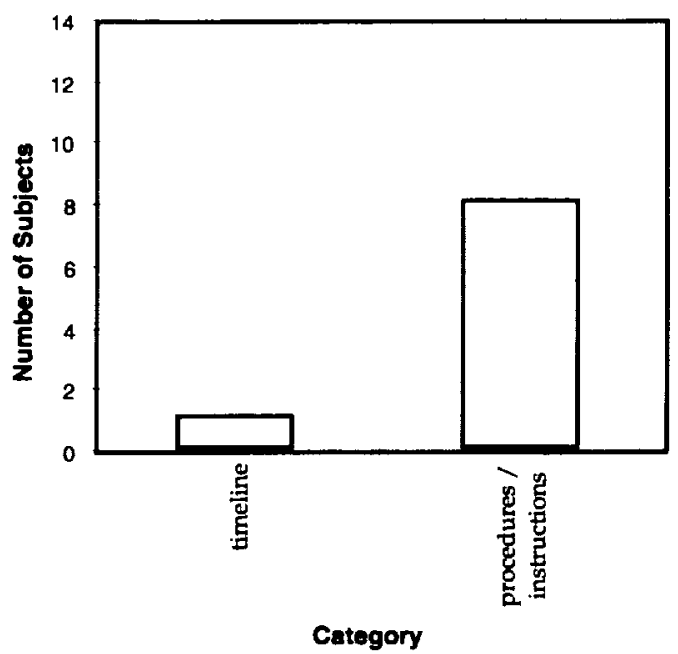

Equipment/Systems - Example

III

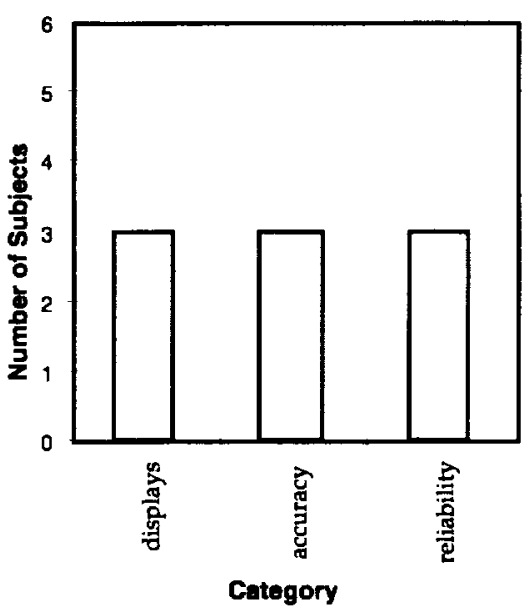

B-6 
Environment - Example IV

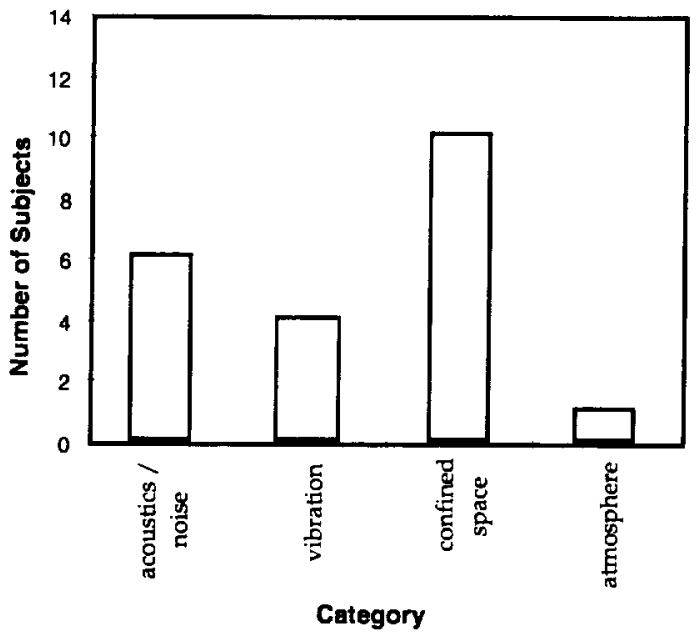

Human - Example IV

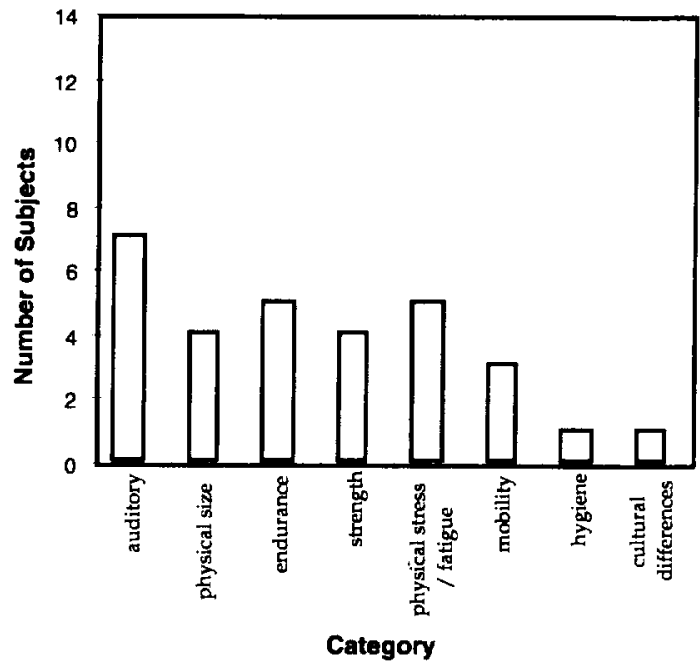

B-7 
Operational - Example IV

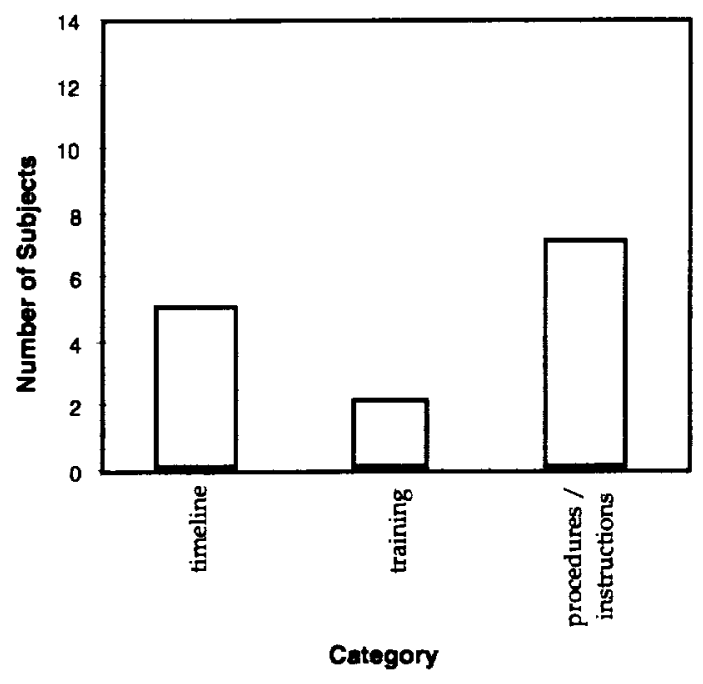

Equipment/Systems

Example IV

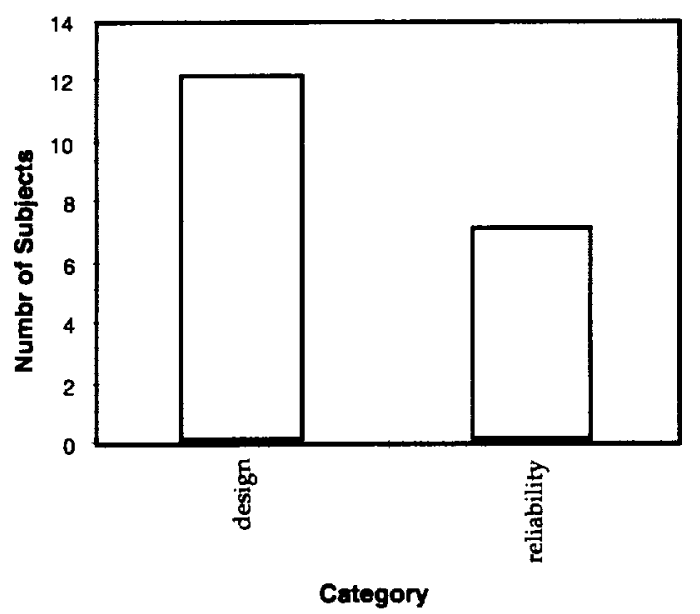

B-8 

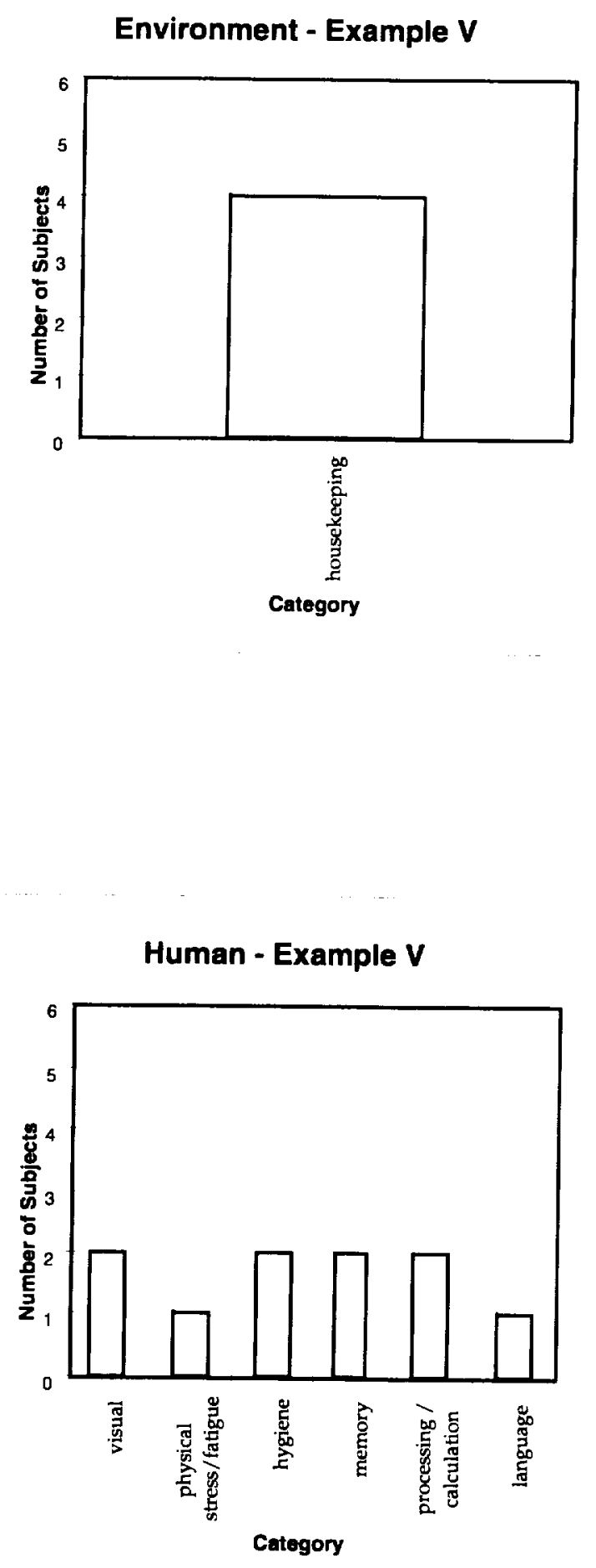
Operational - Example V

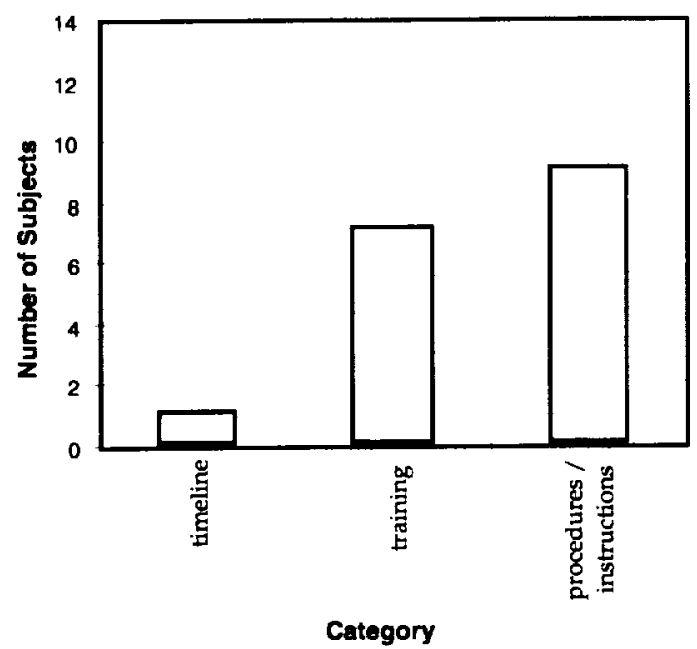

Equipment/Systems

Example V

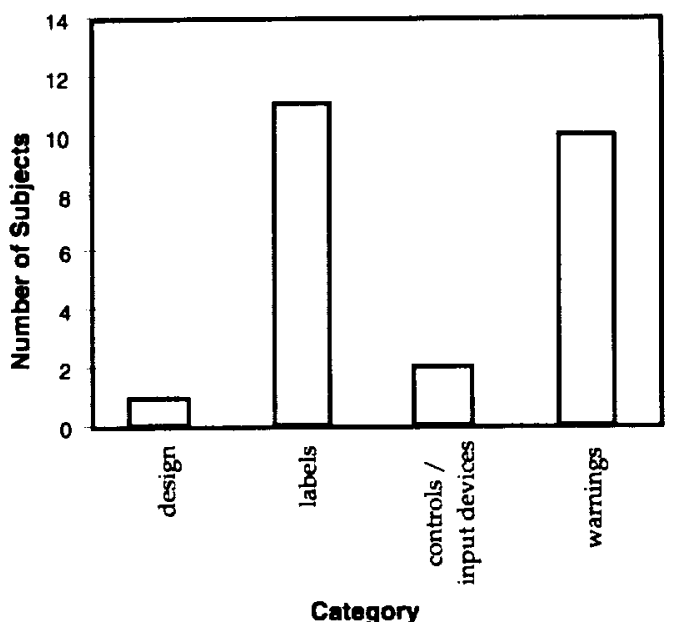

B-10 
Environment - Example VI

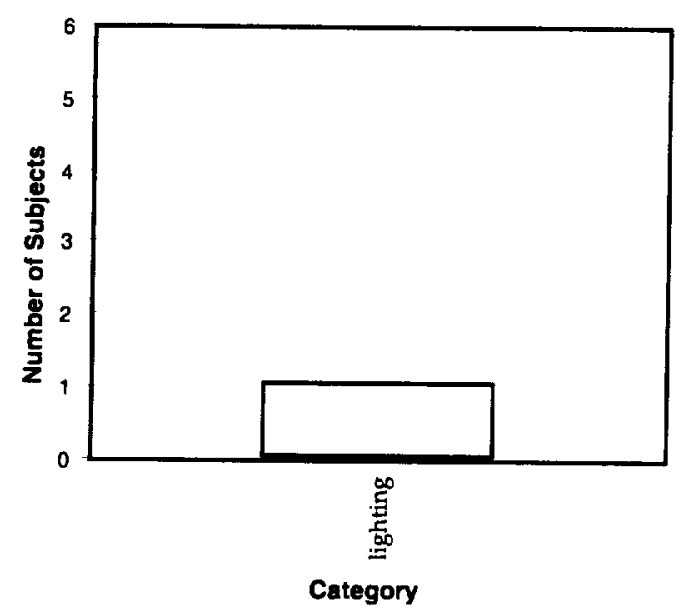

Human - Example Vı

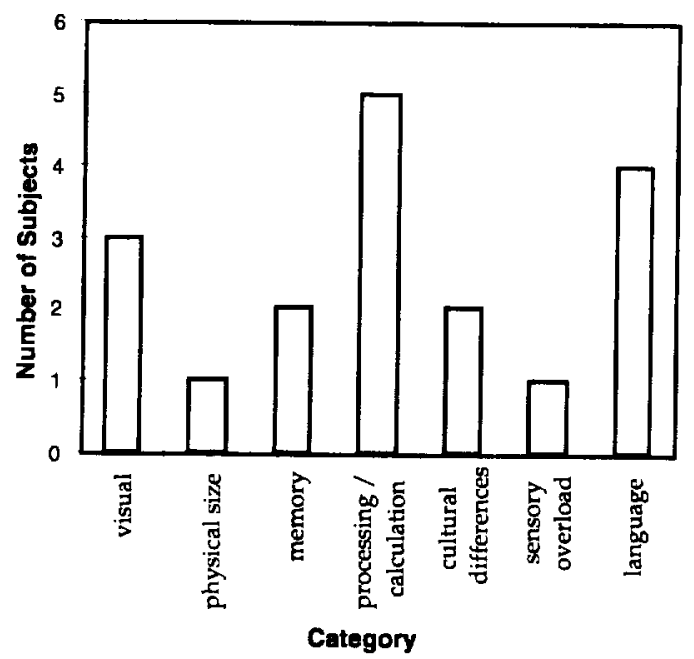

B-11 


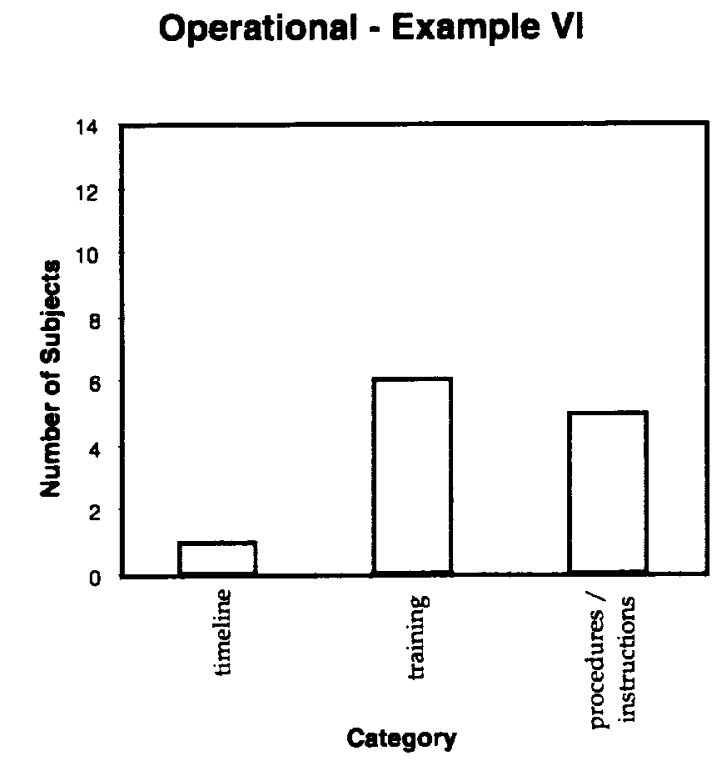

Equipment/Systems

Example VI

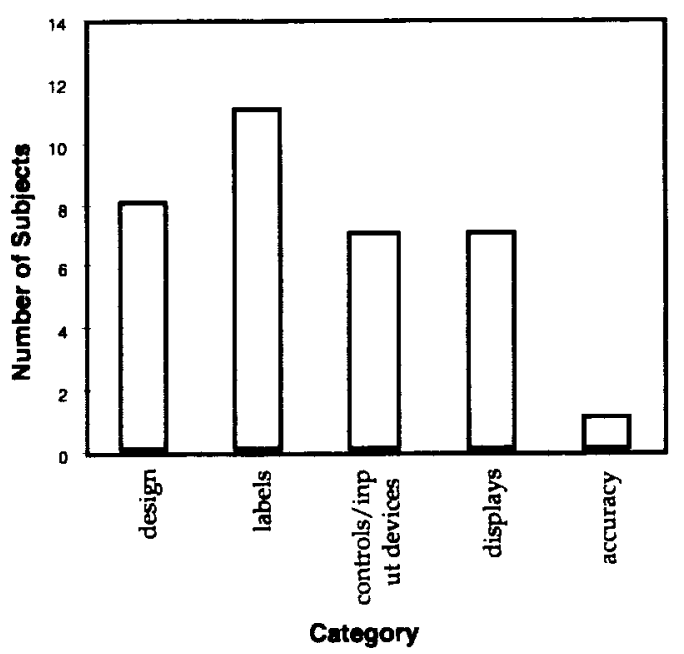

B-12 

Development of the Space Operations Incident Reporting Tool (SOIRT)

5. FUNDING NUMBERS

6. AUTHOR(S)

Jacquie Minton

7. PERFORMING ORGANIZATION NAME(S) AND ADDRESS(ES)

Lyndon B. Johnson Space Center

8. PERFORMING ORGANIZATION REPORT NUMBERS

Houston, Texas 77058

$S-820$

9. SPONSORING/MONITORING AGENCY NAME(S) AND ADDRESS(ES)

10. SPONSORING/MONITORING AGENCY REPORT NUMBER

National Aeronautics and Space Administration TP-3660

Washington, DC 20546-0001

11. SUPPLEMENTARY NOTES

12a. DISTRIBUTIONAVAILABILITY STATEMENT

Unclassified/Unlimited

Available from the NASA Center for Aerospace Information (CASI)

800 Elkridge Landing Road, Linthicum Heights, MD 21090-2934

(301) 621-0390

Subject Category: 54

\section{ABSTRACT (Maximum 200 words)}

The space operations incident reporting tool (SOIRT) is an instrument used to record information about an anomaly occurring during flight which may have been due to insufficient and/or inappropriate application of human factors knowledge. We originally developed the SOIRT form after researching other incident reporting systems of this type. We modified the form after performing several in-house reviews and a pilot test to access usability. Finally, crew members from Space Shuttle flights participated in a usability test of the tool after their missions.

Since the National Aeronautics and Space Administration (NASA) currently has no system for continuous collection of this type of information, the SOIRT was developed to report issues such as reach envelope constraints, control operation difficulties, and vision impairments. However, if the SOIRT were to become a formal NASA process, information from crew members could be collected in a database and made available to individuals responsible for improving in-flight safety and productivity. Potential benefits include documentation to justify the redesign or development of new equipment/systems, provide the mission planners with a method for identifying past incidents, justify the development of timelines and mission scenarios, and require the creation of more appropriate work/rest cycles.

\section{SUBNECT TERMS}

forms (paper), space transportation system, reports, postflight analysis, postmission analysis, anomalies, human factors engineering

15. NUMBER OF PAGES

25

\section{SECURITY CLASSIFICATION OF REPORT \\ Unclassified

18. SECURITY CLASSIFICATION
OF THIS PAGE
Unclassified SECURITY CLASS
OF THIS PAGE}

19. SECURITY CLASSIFICATION OF ABSTRACT

Unclassified
16. PRICE CODE

Standard Form 298 (Rey Fob 89) (MS Word Mar 97)

Prescribed by ANSI Std. $239-18$

298-102 